\title{
Oral potentially malignant disorders in a large dental population
}

\author{
Alessandro VILLA 1 , Anita GOHEL ${ }^{2}$ \\ 1- Division of Oral Medicine and Dentistry, Brigham and Women's Hospital, and Department of Oral Medicine, Infection and Immunity, Harvard School of \\ Dental Medicine, Boston MA. \\ 2- Department of General Dentistry, Boston University Henry M. Goldman School of Dental Medicine, Boston, MA, United States.
}

Corresponding address: Dr. Alessandro Villa - Division of Oral Medicine and Dentistry, Brigham and Women's Hospital - 1620 Tremont Street, Suite BC-3028 - Boston - MA 02120 - Phone: 617-732-5517 - Fax: 617-232-8970 - e-mail: avilla@partners.org

Submitted: July 8, 2014 - Modification: September 8, 2014 - Accepted: September 11, 2014

\section{ABSTRACT}

\begin{abstract}
$\mathrm{O}$ bjectives: Oral cancer $(O C)$ may be preceded by clinically evident oral potentially malignant disorders (OPMDs). Oral carcinogenesis is a multistep process that begins as epithelial hyperplasia and progresses to oral epithelial dysplasia and finally to fully malignant phenotypes. The aim of our study was to estimate the prevalence of OPMDs in a large population of dental patients. Methods: Patients were seen in the Oral Diagnosis and Oral Medicine clinics at Boston University Henry M. Goldman School of Dental Medicine between July 2013 and February 2014 and received a comprehensive oral examination to identify any possible mucosal lesions. Patients with a suspected OPMD (submucous fibrosis, oral lichen planus, leukoplakia and erythroplakia) that did not resolve in 2-3 weeks received a biopsy for definitive diagnosis. Logistic regression models were used to explore the relationship between OPMDs and associated risk factors. Results: A total of 3,142 patients received a comprehensive oral examination [median age: 43 (range: $18-97) ; 54.3 \%$ females]. Among these, $4.5 \%$ had an oral mucosal lesion with $0.9 \%$ being an OPMD (one submucous fibrosis, three epithelial dysplasias, fourteen with hyperkeratosis/ epithelial hyperplasia and nine with oral lichen planus). Males and current smokers were associated with higher odds of having OPMD (OR 1.7, 95\% $\mathrm{Cl} 0.8-3.8 ; \mathrm{OR} 1.9,95 \% \mathrm{Cl}$ $0.8-4.1)$. Increasing age was associated with having OPMDs $(p<0.01)$. Conclusion: Optimal oral visual screening for $\mathrm{OC}$ remains a simple and essential tool to identify any suspicious lesions and potentially increase survival. Although OPMDs were rare, our results confirm the importance of a thorough chairside screening by dentists and dental students to detect any mucosal changes.
\end{abstract}

Keywords: Oral mucosa. Leukoplakia. Screening.

\section{NTRODUCTI ON}

Almost 263,020 oral cavity cancers, and 127,654 oral cancer deaths occur worldwide each year ${ }^{9}$. On January 1, 2010, in the US there were around 275,193 women and men alive who had a history of oral and oro-pharyngeal cancer $(181,084$ men and 94,109 women) ${ }^{18}$. The 5 -year survival rate of patients with oral cancer remains almost unchanged regardless of various treatment improvements in the last thirty years ${ }^{11}$. Individuals at high risk of developing oral cancer $(O C)$ are mainly older, males, heavy tobacco smokers and alcohol users, and have a poor diet and low socioeconomic status ${ }^{5,13}$.
Recent studies have implicated HPV infection as an independent risk factor for oro-pharyngeal cancers ${ }^{6,10}$.

Oral squamous cell carcinoma initiates in a multistep process in which normal cells are transformed into preneoplastic cells and then to cancer ${ }^{20}$. During this process, a sequential accumulation of genetic and molecular changes occur 22 . The majority of oral cancers are preceded by visible changes of the oral mucosa. Within the oral cavity, lesions such as leukoplakia, erythroplakia, lichen planus and submucous fibrosis have a propensity for malignancy ${ }^{17}$. Oral potentially malignant disorders (OPMD) transform to oral cancers through various 
histopathological stages from hyperkeratosis/ hyperplasia, to various degrees of dysplasia (categorized by mild, moderate, or severe according to the presence and severity of cell atypia and other structural aspects of the epithelium), to carcinoma in situ (CIS), and finally to invasive cancer ${ }^{26}$. Histopathological evaluation for the grade of epithelial dysplasia is the most common method used to ascertain malignant potential of individuals with oral pre-cancerous lesions ${ }^{21}$.

Early detection for oral cancer has the potential to decrease the morbidity and mortality of the disease, especially in high-risk individuals ${ }^{8}$. To date only one randomized clinical trial evaluated the effect of oral cancer screening and demonstrated that periodic oral examination has the potential to reduce mortality from oral cancer in high-risk individuals ${ }^{23}$. Visual and tactile examination remains the most common tool available to detect any mucosal changes and requires a 90-s exam, yet few oral health care providers are conducting a thorough oral mucosal exam. The aim of the present study was to 1 ) estimate the prevalence of OPMDs and 2) identify the associated risk factors in a large dental population.

\section{MATERI AL AND METHODS}

\section{Study population}

All new patients aged 18 or older, attending the Oral Diagnosis Clinic in the Department of General Dentistry at Boston University Henry M. Goldman School of Dental Medicine from July 8, 2013, through March 8, 2014 were included in this study. A written consent was obtained from each participant. The study was approved by the Boston University Medical Campus Institutional Review Board. Each patient was asked questions on: socio-demographic information including age and gender; self-reported medical history; family history of cancer; tobacco smoking and alcohol consumption; height and weight to determine body mass index (BMI). A thorough visual oral soft tissue examination was performed on each patient by a dental student first and then by an attending dentist to identify any OPMD or any other mucosal lesion using mouth mirrors and a sterile piece of gauze to retract the tongue ${ }^{24}$. The diagnostic criteria for the recognition of OPMD (erythroplakia, leukoplakia, oral lichen planus and submucous fibrosis) were based on the WHO recommendations ${ }^{12,26}$. Although oral lichen planus is classified as an OPMD there is still controversy on its pre-malignant nature ${ }^{17}$. Only oral lichen planus patients with an ulcerative component were included in this analysis. Patients with leukoplastic and/or erythroplastic lesions and without a definitive clinical diagnosis were reevaluated and considered for biopsy for diagnostic purposes (Figure 1$)^{19}$. Individuals with OPMD were considered as cases and those without any OPMD as controls.

\section{Statistical analysis}

We described the distribution of patient characteristics, including demographics, tobacco smoking, and daily alcohol consumption. To explore the association between OPMDs and risk factors that might be expected to be associated with OPMDs, we used logistic regression models to estimate the odds ratios (ORs) and 95\% confidence intervals (CIs). Statistical analyses were performed using STATA, version 9.2 (Stata Corp LP, College Station, TX, USA). For all analyses, a $\mathrm{P}$ value of $<0.05$ (2-tailed) was considered statistically significant.

\section{RESULTS}

A total of 3,142 patients ( $54.3 \%$, females) received a comprehensive examination of the oral cavity (Table 1). At the time of the oral exam, patients ranged in age from 18 to 97 years, with a median age of 43 years. Tobacco smoking and alcohol consumption was reported in $75.8 \%$ and $63.9 \%$ of the individuals, respectively. A total of 142 patients $(4.5 \%)$ were identified as having a mucosal lesion (78 white lesions, 30 ulcerative lesions, 34 mixed lesions; Figure 1) among these, 37 patients $(1.2 \%)$ had a suspicious OPMD and received an oral biopsy for definitive diagnosis. Twenty-seven individuals $(0.9 \%)$ had a final diagnosis of OPMDs. One patient was affected by submucous fibrosis, three were diagnosed with leukoplakia and nine with oral lichen planus. None of the patients had a diagnosis of oral cancer.

Male patients were associated with higher odds of having OPMD (OR 1.7, 95\% Cl 0.8-3.8; $p=0.16$; Table 2). Individuals who were current tobacco smokers were twice as likely to have an OPMD (OR $1.9,95 \% \mathrm{Cl} 0.8-4.1 ; p=0.12$ ) compared to never

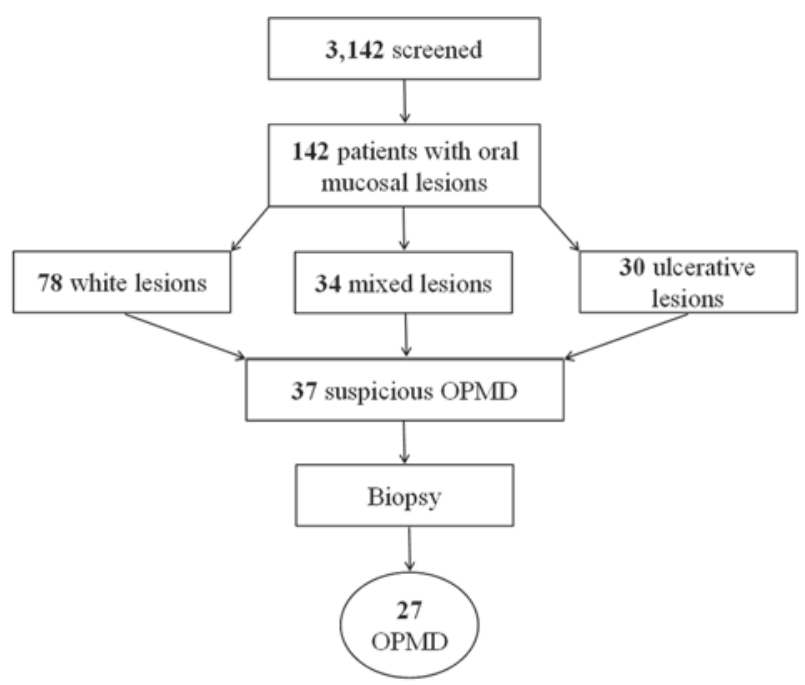

Figure 1- Oral mucosal lesions and oral potentially malignant disorders (OPMDs) in a dental population 
Table 1- Patients characteristics

\begin{tabular}{ccc}
\hline & TOTAL & OPMD \\
& $(\mathbf{N}=\mathbf{3}, \mathbf{1 4 2})$ & $\mathbf{( N = 2 7 )}$ \\
\hline $\mathbf{n}(\%)$ & $\mathbf{n}(\%)$ \\
\hline $18-30$ & $906(28.8)$ & $2(7.5)$ \\
\hline $31-50$ & $1,134(36.1)$ & $12(44.4)$ \\
\hline $50+$ & $1,102(35.1)$ & $13(48.1)$ \\
\hline Median (range) & $43.0(18-97)$ & $49(23-88)$ \\
\hline Gender & & $11(40.7)$ \\
\hline Female & $1,706(54.3)$ & $16(59.3)$ \\
\hline Male & $1,436(45.7)$ & \\
\hline Daily tobacco & & $17(63.0)$ \\
\hline use & & $10(37.0)$ \\
\hline Never & $2,259(75.8)$ & \\
\hline Ever & $722(24.2)$ & $19(70.4)$ \\
\hline $\begin{array}{c}\text { Daily alcohol } \\
\text { consumption }\end{array}$ & & $8(29.6)$ \\
\hline Never & $1,906(63.9)$ & \\
\hline Ever & $1,078(36.1)$ & \\
\hline
\end{tabular}

OPMD: oral potentially malignant disorders

smokers. I ncreasing age was associated with having OPMDs $(p<0.05)$. Daily alcohol consumption did not increase the risk of having an OPMD (OR 0.7. 95\% CI 0.3-1.7; $p=0.48$ ). We observed no significant associations for systemic diseases, BMI and OPMDs (data not shown).

\section{DISCUSSION}

We conducted a large study in a population of dental patients and found that around $1 \%$ had an OPMD upon oral examination (subsequently confirmed by histopathological examination). The oral visual and tactile examination remains a noninvasive tool that can result in earlier diagnosis of OPMDs, but also a large number of other oral mucosal diseases. OPMDs were associated with older age and daily tobacco smoking. Our results are in agreement with other studies on OPMDs. Li, et al. ${ }^{15}$ (2011) showed that smoking was associated with a more than two-fold increase in the odds of having an OPMD (OR 2.5, 95\% Cl: 1.3-4.8). Chung, et al. $^{3}$ (2005) reported that individuals who were current smokers had a 4.7 -fold $(95 \% \mathrm{Cl}$ : 3.2-6.8) increased risk of having an OPMD. However, when alcohol consumption was considered, we did not find any statistical significant association with OPMDs whereas Chung, et al. $^{3}$ (2005) found that OPMDs among individuals reporting alcohol drinking were significantly higher than in non-drinkers (OR 3.6, 95\% Cl: 2.4-5.3).
Table 2- Multivariate analysis for oral potentially malignant disorders

\begin{tabular}{|c|c|c|c|c|}
\hline & \multicolumn{4}{|c|}{ OPMD } \\
\hline & $\begin{array}{c}\text { No } \\
(\mathrm{N}=3,115)\end{array}$ & $\begin{array}{c}\text { Yes } \\
(\mathrm{N}=27)\end{array}$ & $\begin{array}{c}\text { Odds } \\
\text { ratio } \\
(95 \% \mathrm{Cl})\end{array}$ & $\begin{array}{l}p \text { for } \\
\text { trend }\end{array}$ \\
\hline \multicolumn{5}{|l|}{ Age } \\
\hline $18-30$ & $\begin{array}{c}904 \\
(99.8)\end{array}$ & $\begin{array}{c}2 \\
(0.2)\end{array}$ & 1.0 & $<0.01$ \\
\hline $31-50$ & $\begin{array}{l}1,122 \\
(98.9)\end{array}$ & $\begin{array}{c}12 \\
(1.1)\end{array}$ & $\begin{array}{c}4.8 \\
(1.1-21.7)\end{array}$ & \\
\hline $50+$ & $\begin{array}{l}1,089 \\
(98.8)\end{array}$ & $\begin{array}{c}13 \\
(1.2)\end{array}$ & $\begin{array}{c}5.4 \\
(1.2-24.0)\end{array}$ & \\
\hline \multicolumn{5}{|l|}{ Gender } \\
\hline Female & $\begin{array}{l}1,695 \\
(99.4)\end{array}$ & $\begin{array}{c}11 \\
(0.6)\end{array}$ & 1.0 & 0.16 \\
\hline Male & $\begin{array}{r}1,420 \\
(98.9)\end{array}$ & $\begin{array}{c}16 \\
(1.1)\end{array}$ & $\begin{array}{c}1.7 \\
(0.8-3.8)\end{array}$ & \\
\hline \multicolumn{5}{|c|}{$\begin{array}{c}\text { Daily tobacco } \\
\text { use }\end{array}$} \\
\hline Never & $\begin{array}{l}2,242 \\
(99.3)\end{array}$ & $\begin{array}{c}17 \\
(0.7)\end{array}$ & 1.0 & 0.12 \\
\hline Ever & $\begin{array}{c}712 \\
(98.6)\end{array}$ & $\begin{array}{c}10 \\
(1.4)\end{array}$ & $\begin{array}{c}1.9 \\
(0.8-4.1)\end{array}$ & \\
\hline \multicolumn{5}{|c|}{$\begin{array}{l}\text { Daily alcohol } \\
\text { consumption }\end{array}$} \\
\hline No & $\begin{array}{l}1,887 \\
(99.0)\end{array}$ & $\begin{array}{c}19 \\
(1.0)\end{array}$ & 1.0 & 0.48 \\
\hline Yes & $\begin{array}{l}1,070 \\
(99.3)\end{array}$ & $\begin{array}{c}9 \\
(0.7)\end{array}$ & $\begin{array}{c}0.7 \\
(0.3-1.7)\end{array}$ & \\
\hline
\end{tabular}

OPMD: oral potentially malignant disorders

Our findings support that oral cancer screenings should not be a separate procedure rather they should be part of the complete dental examination for all patients ${ }^{7}$. Primary prevention of OSCC should focus on the prevention of cancer by avoiding known carcinogens (e.g., heavy tobacco consumption) ${ }^{2}$. Secondary cancer prevention includes early detection of cancer through screening programs in a population at risk and asymptomatic, as well as prevention of the transformation of OPMDs ${ }^{25}$. Dentists and all members of the oral health team have the unique opportunity to prevent smoking uptake and promote smoking cessation among their patients and may therefore reduce the prevalence of OPMDs ${ }^{14}$. In addition, patients at high risk may be referred to specialists for behavioral counseling interventions to reduce tobacco use or heavy alcohol consumption ${ }^{16}$. Oral mucosal lesions are easily detected through direct visualization, and so oral health providers, otolaryngologists, primary care physicians and 
nurse practitioners should be effectively trained to perform a comprehensive oral mucosal examination and identify abnormal lesions ${ }^{1}$.

As in all studies, our results must be interpreted in the context of the limitations of the investigation. First, only few cases of OPMDs were identified. Larger studies are necessary to further explore the association between smoking tobacco, alcohol consumption and OPMDs. Second, our results may not be generalizable to the population at large, as only dental patients were included. Randomizedcontrolled trials may be useful to further investigate the sensibility and specificity of the oral visual examination in the context of OPMDs.

The Commission on Dental Accreditation (CODA) in the United States has recently approved a new dental curriculum to help dental students become proficient in oral cancer screening (Comprehensive General Dentistry, CODA 2-23 b) ${ }^{4}$. Optimal oral visual screening for $\mathrm{OC}$ remains a simple and essential tool to identify any suspicious lesions and potentially increase survival.

\section{CONCLUSION}

A thorough visual and tactile examination in dental patients, particularly those with a history of smoking and elderly is warranted. Dentists and dental students should stay alert for signs of oral potential malignancy and counsel their patients about risk factors for oral cancer. Although OPMDs were rare, our results confirm the importance of a thorough chairside screening by dentists to detect any mucosal changes.

\section{CONFLI CT OF I NTEREST}

The authors have no competing financial interests to declare.

\section{REFERENCES}

1- Applebaum E, Ruhlen TN, Kronenberg FR, Hayes C, Peters ES. Oral cancer knowledge, attitudes and practices: a survey of dentists and primary care physicians in Massachusetts. J Am Dent Assoc. 2009; 140:461-7.

2- Blackburn EH. Highlighting the science of cancer prevention. Cancer Prev Res (Phila). 2010; 3:393.

3- Chung $\mathrm{CH}$, Yang YH, Wang TY, Shieh TY, Warnakulasuriya S. Oral precancerous disorders associated with areca quid chewing, smoking, and alcohol drinking in southern Taiwan. J Oral Pathol Med. 2005;34(8): 460-6.

4- Commission on Dental Accreditation. Accreditation standards for dental education programs [online]. July, 2013. [cited J une 12, 2014]. Available from: http://www.ada.org/ /media/CODA/Files/ predoc_2013.ashx.

5- Conway DI, Petticrew M, Marlborough H, Berthiller J, Hashibe M, Macpherson LM. Socioeconomic inequalities and oral cancer risk: a systematic review and meta-analysis of case-control studies. Int J Cancer. 2008; 122:2811-9.
6- D'Souza G, Kreimer AR, Viscidi R, Pawlita M, Fakhry C, Koch $W M$, et al. Case-control study of human papillomavirus and oropharyngeal cancer. N Engl J Med. 2007; 356: 1944-56.

7- Edwards PC. Oral cancer screening for asymptomatic adults: do the United States Preventive Services Task Force draft guidelines miss the proverbial forest for the trees? Oral Surg Oral Med Oral Pathol Oral Radiol. 2013; 116:131-4.

8- Fedele S. Diagnostic aids in the screening of oral cancer. Head Neck Oncol. 2009; 1:5.

9- Ferlay J, Shin HR, Bray F, Forman D, Mathers C, Parkin DM. Estimates of worldwide burden of cancer in 2008: GLOBOCAN 2008. Int J Cancer. 2010; 127:2893-917.

10- Gillison ML, Koch WM, Capone RB, Spafford M, Westra WH, $\mathrm{Wu} L$, et al. Evidence for a causal association between human papillomavirus and a subset of head and neck cancers. J Natl Cancer Inst. 2000; 92:709-20.

11- Jemal A, Siegel R, Ward E, Hao Y, Xu J, Murray T, et al. Cancer statistics, 2008. CA Cancer J Clin. 2008;58:71-96.

12- Kramer IR, Pindborg JJ, Bezroukov V, Infirri JS. Guide to epidemiology and diagnosis of oral mucosal diseases and conditions. World Health Organization. Community Dent Oral Epidemiol. 1980; 8: 1-26.

13- Leemans CR, Braakhuis BJ, Brakenhoff RH. The molecular biology of head and neck cancer. Nat Rev Cancer. 2011;11:9-22.

14- Li L, Morse DE, Katz RV. What constitutes a proper routine oral cancer examination for patients at low risk? Findings from a Delphi survey. Oral Surg Oral Med Oral Pathol Oral Radiol. 2013; 116: e379-86.

15- Li L, Psoter WJ, Buxó CJ , Elias A, Cuadrado L, Morse DE. Smoking and drinking in relation to oral potentially malignant disorders in Puerto Rico: a case-control study. BMC Cancer. 2011;11: 324.

16- Moyer VA, U.S. Preventive Services Task Force. Screening for oral cancer: U.S. Preventive Services Task Force recommendation statement. Ann Intern Med. 2014; 160: 55-60.

17- Napier SS, Speight PM. Natural history of potentially malignant oral lesions and conditions: an overview of the literature. J Oral Pathol Med. 2008; 37: 1-10.

18- National Cancer Institute. SEER Cancer Statistics Review, 19752010 [online]. 2013. [cited July 8, 2014]. Available from: http:// seer.cancer.gov/csr/1975_2010/.

19- National Institute of Dental and Craniofacial Research. Detecting oral cancer: a guide for health care professionals [online]. July, 2013. [cited May 1, 2014]. Available from: http://www. nidcr.nih. gov/oralhealth/topics/oralcancer/detectingoralcancer.htm.

20- Pérez-Sayáns M, Somoza-Martín JM, Barros-Angueira F, Reboiras-López MD, Gándara Rey J M, García-García A. Genetic and molecular alterations associated with oral squamous cell cancer (Review). Oncol Rep. 2009;22(6):1277-82.

21- Reibel J. Prognosis of oral pre-malignant lesions: significance of clinical, histopathological, and molecular biological characteristics. Crit Rev Oral Biol Med. 2003; 14:47-62.

22- Renan MJ. How many mutations are required for tumorigenesis? Implications from human cancer data. Mol Carcinog. 1993; 7: 13946.

23- Sankaranarayanan R, Ramadas K, Thomas G, Muwonge R, Thara $S$, Mathew $B$, et al. Effect of screening on oral cancer mortality in Kerala, India: a cluster-randomised controlled trial. Lancet. 2005; 365: 1927-33.

24- Scully C. Clinical diagnostic methods for the detection of premalignant and early malignant oral lesions. Community Dent Health. 1993; 10(Suppl 1):43-52.

25- Smith RA, Cokkinides V, Brawley OW. Cancer screening in the United States, 2012: a review of current American Cancer Society guidelines and current issues in cancer screening. CA Cancer J Clin. 2012. doi: 10.3322/caac.20143. Epub ahead of print.

26- Warnakulasuriya S, J ohnson NW, van der Waal I. Nomenclature and classification of potentially malignant disorders of the oral mucosa. J Oral Pathol Med. 2007; 36:575-80. 